\title{
Correction of refractive error in the Victorian population: the feasibility of "off the shelf" spectacles
}

\author{
Raj Maini, Jill Keeffe, Le Ann Weih, Catherine A McCarty, Hugh R Taylor
}

\begin{abstract}
Aims-To assess the feasibility of providing a stock of ready made spectacles for correction of refractive error in the general population.

Methods-Data were collected in the Visual Impairment Project, a population based survey of Victorian residents aged 40 years or older in randomly selected urban and rural sample areas. This included a refractive eye examination and the proportion of subjects with hypermetropia, emmetropia (defined as -1.0 to +1.0D spherical equivalent), and myopia documented in the 40-60 year age group. Results-2595 (54.8\%) participants were aged between 40 and 60 years. Those with a best corrected visual acuity of less than $6 / 12$, astigmatism of more than $1.25 \mathrm{D}$, and anisometropia of more than $0.5 \mathrm{D}$ were excluded. 516 participants had refractive error which was deemed suitable for correction by "off the shelf" spectacles. This represents $19.9 \%$ of all participants between 40 and 60 years of age. Provision of spectacles in $0.5 \mathrm{D}$ increments would provide suitable stock spectacles for $85.5 \%$ of a -3.0 to $+3.0 \mathrm{D}$ range or $89.2 \%$ of a -3.50 to $+3.50 \mathrm{D}$ range.

Conclusions-Ready made "off the shelf" spectacles could significantly alleviate visual morbidity due to refractive error in up to $20 \%$ of an urban population in Australia. This approach may also be useful in developing countries with poor access to optometric services.

(Br f Ophthalmol 2001;85:1283-1286)
\end{abstract}

Research Australia, Melbourne, Australia

R Maini

J Keeffe

L A Weih

C A McCarty

H R Taylor

Correspondence to: Dr J Keeffe, Centre for Eye Research Australia,

University of Melbourne, 32 Gisborne Street, East

Melbourne, Victoria 3002, Australia

jillek@unimelb.edu.au

Accepted for publication 21 June 2001 with refractive error in their sample were not wearing distance correction. ${ }^{4}$ The Blue
Mountains Eye Study found that refraction improved acuity in $45 \%$ of participants. ${ }^{3}$

Refractive error is one of the five priority areas for "Vision 2020," the global initiative for the elimination of preventable blindness by the year $2020 . .^{5}$ It represents a common condition that can be cheaply remedied (by spectacles) with a resultant significant functional and lifestyle improvement. It has also been demonstrated that uncorrected refractive error is associated with higher mortality ${ }^{6}$ and morbidity from hip fractures and falls. ${ }^{7}$

However, there still exists a lack of knowledge on the global prevalence of refractive errors; recent studies have attempted to address this gap in our knowledge. Wong et al found that $74.2 \%$ of Singaporean Chinese between the age of 40 and 79 years had myopia or hyperopia ranging from $-5.0 \mathrm{D}$ to $5.0 \mathrm{D}$ (excluding emmetropes). ${ }^{8}$ It is estimated that more than $7 \%$ of Chilean children could benefit from the provision of proper spectacles ${ }^{9}$ and that refractive error was the cause in 56\% of those children with reduced vision. Zhao et al studying a rural population in China found that myopia $(<-0.5 \mathrm{D})$ increased from an insignificant prevalence at age 5 years to $37 \%$ for males and $55 \%$ for girls aged 15 years. ${ }^{10}$ Similar figures of prevalence have been noted in the "developed" world: the Visual Impairment Project found a prevalence of myopia of $24 \%$ in those aged 40-49 years in Victoria, ${ }^{11}$ and the Blue Mountains Eye Study found a prevalence of myopia and hyperopia of $72 \%$ for an Australian population aged between 49 and 97 years. $^{12}$

The global population will increase from 5.8 billion in 1996 to 7.9 billion in 2020, with an increase in the population aged over 45 years from one billion to two billion over the same period. ${ }^{13}$ Most of this increase will take place in the developing world and will mean an increasing demand for refractive correction.

In many countries, poor supply of refraction services, supply of spectacles, and economic factors may limit access of the general population to refractive correction. The cost of individually made up spectacles would be prohibitive for large scale supply in many developing areas. The provision of ready made spectacles provided in bulk at low cost across a range of refractive corrections could potentially 
reduce this cost. Ready made spectacles have already shown great benefit with reading spectacles readily available for the presbyopic population.

The VIP found that $10 \%$ of participants in the project had undercorrected refractive error improvable by one or more lines of visual acuity on refraction, ${ }^{14}$ and the risk for this increased by a factor of 1.8 for each decade of life after age 40 years. Overall, $60 \%$ of participants presenting with visual acuity of less than 6/6-2 improved their acuity by one line or more after refraction. ${ }^{14}$ The present study used the VIP population to examine the feasibility of providing an "off the shelf" supply of spectacles for the correction of refractive error in the communities that may not have resources available to support formal optometric services.

\section{Methods}

The Visual Impairment Project was a population based survey of Victorian residents aged 40 years or older and the methodology is described in detail elsewhere. ${ }^{15}$ Participants were identified by a doorstep private census in nine randomly selected urban sample areas and four randomly selected rural sample areas comprising adjacent pairs of 1986 census collector districts. Data were collected from 1992 to 1996. Once identified participants were interviewed regarding demographic data and use of spectacles or contact lenses, and invited to attend the free eye examination at the local screening centre.

The refractive eye examination comprised measurement of the participant's current optical correction using the Humphrey automatic lens analyser model $330,{ }^{16}$ and measurement of the presenting visual acuity using the ETDRS (Early Treatment of Diabetic Retinopathy) ${ }^{17}$ letter chart, based on the $\log$ MAR visual acuity chart developed by Bailey and Lovie. ${ }^{18} \mathrm{~A}$ directional $\mathrm{E}$ chart was used for those who did not know the Latin alphabet. If the visual acuity was less than $6 / 7.5(20 / 25)$ in either eye, an objective and subjective refraction was conducted using the Humphrey automatic refractor (Carl Zeiss Pty Ltd, Germany). ${ }^{19}$ A manual refraction was then attempted on all participants (using the Humphrey objective as a

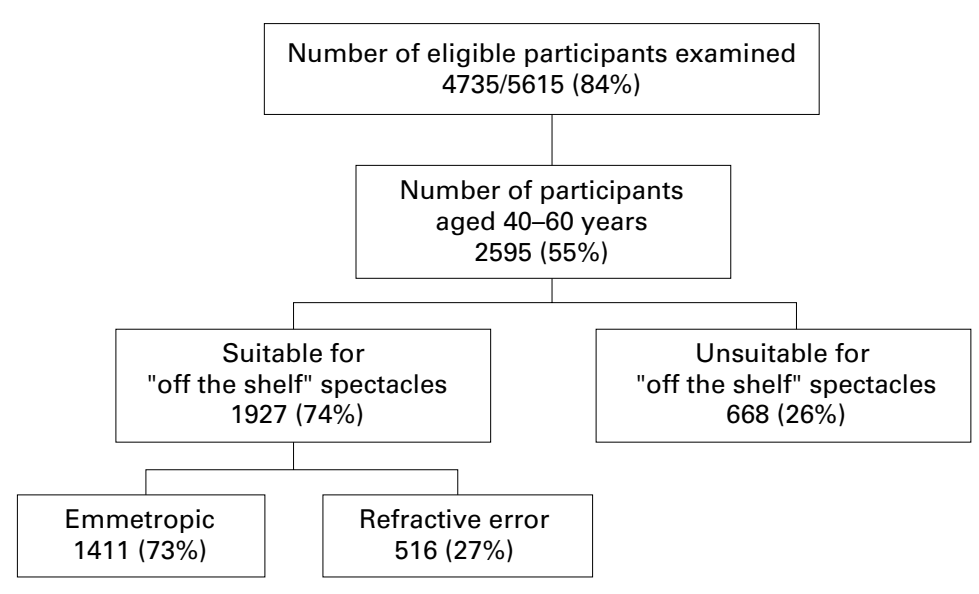

Figure 1 Participants eligible for "off the shelf" spectacles. guideline). The presence or absence of distance optical correction in those with refractive error was recorded.

Best corrected near visual acuity was measured using the $\log$ MAR word reading card (designed for use at $25 \mathrm{~cm}$ ) used at the participant's preferred reading distance, which was recorded.

The type of refractive error was based on spherical equivalent ${ }^{20}$ (although astigmatism and anisometropia were also assessed) and divided into hypermetropia, emmetropia, and myopia. Emmetropia was defined as refractive error $>-1.0$ and $<+1.0$ dioptre (D), myopia defined as $-1.0 \mathrm{D}$ or less and hypermetropia as $+1.0 \mathrm{D}$ or more.

Data analyses were performed with sAS software (SAS institute, Cary, NC, USA).

Feasibility of use of "off the shelf" spectacles was considered to be greater in the 40-60 year age group as above this age other ocular morbidities become more frequent, decreasing the best corrected visual acuity (BCVA). The present study was therefore limited to this age cohort. The ametropic subjects were divided into half dioptre steps to maximise the benefit (in terms of BCVA) to a population to be served by this provision.

\section{Results}

A total of 5615 eligible residents were identified (3912 urban and 1703 rural), of who 4735 (84\%) completed vision assessment; 2595 (54.8\%) participants were aged between 40 and 60 years and were included in these analyses. Of these, $87(3.4 \%)$ had a presenting best corrected visual acuity of more than $6 / 12$ in either eye and were therefore excluded as visual potential was limited by ocular morbidity other than refractive error. Anisometropia of more than $0.5 \mathrm{D}$ was found in 275 patients, astigmatism of $1.25 \mathrm{D}$ or more in 171 , and both in 135 patients, giving a total of 581/2595 (22.4\%) who were deemed unsuitable for "off the shelf" spectacles and therefore excluded from the present study.

This left $1927(74.3 \%)$ who would be suitable for "off the shelf" spectacles if needed. Of these $1411(73.2 \%)$ were emmetropic (defined as -1.0 to $+1.0 \mathrm{D}$ spherical equivalent). Therefore, 516/1927 (26.8\%) participants had low astigmatic (less than 1.25D) or non-astigmatic refractive error and would be suitable for "off the shelf" spectacles depending on the range of dioptric power stocked (Fig 1 ). This represents $19.9 \%$ of all participants between 40 and 60 years of age.

The supplied range of "off the shelf" spectacles available could be limited from +3.0 to $-3.0 \mathrm{D}$ or +3.5 to $-3.5 \mathrm{D}$ in $0.5 \mathrm{D}$ increments. Analysis of the distribution of refractive error from the VIP across these ranges is outlined in Table 1.

The range of +3.0 to $-3.0 \mathrm{D}$ with 12 half dioptre steps would provide suitable stock spectacles for $441 / 516(85.5 \%)$. This would include $160 / 441$ (36.3\%) participants with correctable myopia and 281/441 (63.7\%) with correctable hyperopia. 
Table 1 Distribution of spectacle power requirement over a $6 D$ or $7 D$ range

\begin{tabular}{|c|c|c|c|c|}
\hline \multirow{2}{*}{$\begin{array}{l}\text { Spherical } \\
\text { equivalent (D) }\end{array}$} & \multicolumn{2}{|l|}{$6 D$ range } & \multicolumn{2}{|l|}{$7 D$ range } \\
\hline & Number & $\%$ & Number & $\%$ \\
\hline-3.5 & & & 13 & 2.83 \\
\hline-3 & 12 & 2.72 & 12 & 2.61 \\
\hline-2.5 & 23 & 5.22 & 23 & 5.00 \\
\hline-2 & 15 & 3.40 & 15 & 3.26 \\
\hline-1.5 & 51 & 11.56 & 51 & 11.09 \\
\hline-1 & 59 & 13.38 & 59 & 12.83 \\
\hline+1 & 115 & 26.08 & 115 & 25.00 \\
\hline+1.5 & 91 & 20.63 & 91 & 19.78 \\
\hline+2 & 45 & 10.20 & 45 & 9.78 \\
\hline+2.5 & 19 & 4.31 & 19 & 4.13 \\
\hline+3 & 11 & 2.49 & 11 & 2.39 \\
\hline+3.5 & & & 6 & 1.30 \\
\hline Total & 441 & & 460 & \\
\hline
\end{tabular}

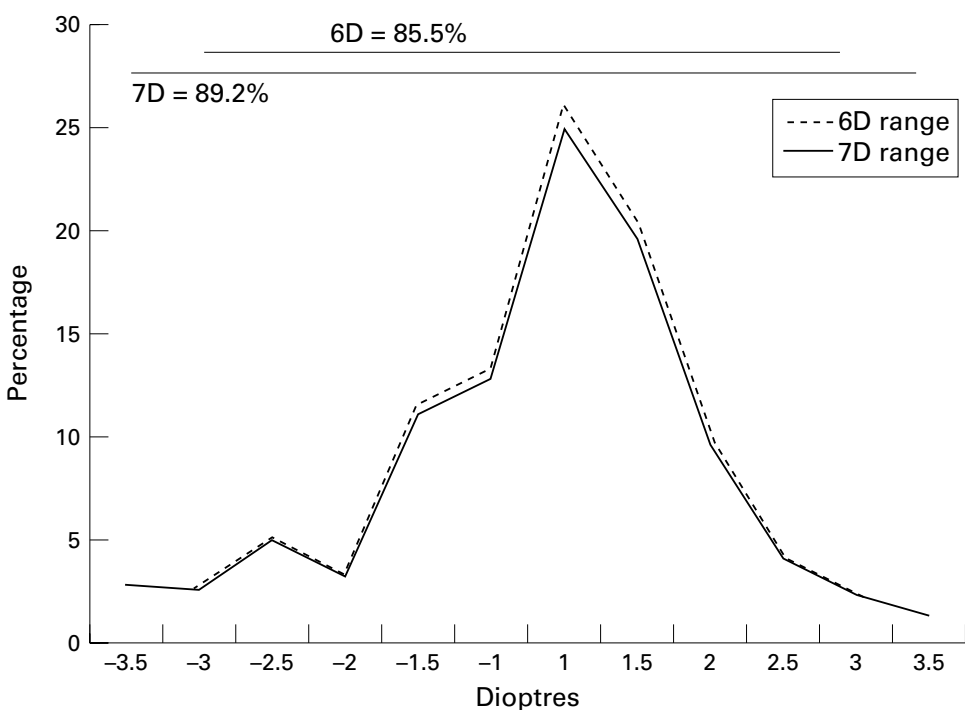

Figure 2 Refractive error versus percentage of subjects. Broken line: $6 \mathrm{D}$ range $(-3.0$ to $+3.0)$. Solid line: $7 D$ range $(-3.5$ to +3.5$)$. Proportion of ametropic population across $6 D$ or $7 D$ range outlined above.

The range of +3.5 to -3.5 with 14 half dioptre steps would provide suitable stock spectacles for $460 / 516(89.2 \%)$. This would include $173 / 460(37.6 \%)$ participants with correctable myopia and $287 / 441(62.4 \%)$ with correctable hyperopia.

\section{Discussion}

This study has found that about $20 \%$ of the Victorian population (both rural and urban) in the age range $40-60$ years would be suitable for refractive correction using "off the shelf" spectacles. We have found that providing stock spectacles across a $6 \mathrm{D}$ and $7 \mathrm{D}$ range would cover $85.5 \%$ and $89.2 \%$ respectively of the non or low astigmatic, non-anisometropic population with refractive error (Fig 2). These figures include all those with refractive error whether already corrected or not. Approximately one third of these participants were myopic, the remaining participants were hyperopic.

The strength of the Visual Impairment Project is that it is truly representative of the population with its inclusion of both a rural and urban sampling within the study population. The population is also multicultural with significant numbers of first generation Australians of South East Asian, Italian, Greek, and Lebanese ancestry, as well as the white population. ${ }^{14}$

Demand for ready made spectacles may be low in urban Australia but this study may be of practical application in diverse communities, especially in countries when optometric resources maybe limited or non-existent. We accept that our study is based in a "developed" community and therefore application of the findings to developing countries may be limited. However, a recent study has found refractive error as a cause of correctable low vision in $19 \%$ of adults over 30 years of age in Bangladesh. ${ }^{21} \mathrm{~A}$ further study reveals $16 \%$ of blindness in participants of all ages was due to refractive error in Andhra Pradesh, India. ${ }^{22}$

Many developing countries do not have optometrists or others trained in refraction or dispensing a prescription of spectacles. Ready made spectacles could easily be provided by paramedical staff with basic training in subjective refraction and dispensing.

The improvement in visual acuity can go to some length to address the aims of Vision 2020 , in some cases bringing a "rudimentary" optometric service to areas where none may have existed heretofore, thus targeting a population who may not have the benefit of regular examinations, health education, and may be on a low income.

The provision of the spectacles should result in improvement in morbidity and mortality, ${ }^{67}$ also alleviating other consequences of poor visual acuity including decreased mobility, quality of life, and independence. The 40-60 year age range also constitutes a significant economic force in most countries and the improved vision has practical implications in this regard. We have not quantified refractive error in younger age groups and further study is required to determine the feasibility of a similar provision for these age ranges that may also benefit greatly from this service. The studies by Maul et $a l^{9}$ and Zhao et $a l^{10}$ illustrate that refractive error is a significant problem in younger age groups in the developing world.

In order to deliver a refractive service to the appropriate populations the steps $^{13}$ to be followed are:

- Screening - to identify individuals who would benefit from the service

- Refraction-evaluation of the patient to determine their suitability for the stock spectacles (a low cost autorefractor would make the least demand in training of use)

- Manufacture-of the spectacles-locally, purchased externally, or donated

- Dispensing-issuing of the spectacles and ensuring a good fit

- Follow up-repair and repeat dispensing.

Effective organisation could feasibly deliver the service to remote communities with poor access to health services generally.

This study has outlined that a campaign to improve the vision of large numbers of people with refractive error in line with Vision 2020 is warranted and feasible with potentially great benefits to be reaped. 
1 Tielsch JM, Sommer A, Witt K, et al. Blindness and visual impairment in an American urban population. Arch Ophthalmol 1990;108:286-90.

2 Klein R, Klein BEK, Linton KLP, et al. The Beaver Dam Eye Study: visual acuity. Ophthalmology 1991;98:1310-15. 3 Attebo K, Mitchell P, Smith W. Visual acuity and the causes of the visual loss in Australia. The Blue Mountains Eye Study. Ophthalmology 1996;103:357-64.

4 Weih LM, Van Newkirk MR, McCarty CA, et al. Age-specific causes of bilateral visual impairment. Arch Ophthalmol 2000;118:264-9.

5 Pararajasegaram R. Vision 2020 - the right to sight: from strategies to action. Am f Ophthalmol 1999;128:359-60.

6 Klein R, Klein BEK, Moss SE. Age related eye disease and survival. The Beaver Dam Eye Study. Arch Ophthalmol 1995;113:333-9.

7 Klein BEK, Klein R, Lee KE, et al. Performance-based and self-assessed measures of visual function as related to history of falls, hip fractures and measured gait time. The Beaver Dam Eye Study. Ophthalmology 1998;105:160-4.

8 Wong TY, Foster PJ, Hee J, et al. Prevalence and risk factors for refractive errors in adult Chinese in Singapore. Invest for refractive errors in adult Chines

9 Maul E, Barroso S, Munoz SR, et al. Refractive error study in children: results from La Florida, Chile. Am $f$ in children: results from

10 Zhao J, Xiangjun P, Ruifang S, et al. Refractive error study in children: results from Shunyi District, China. Am $f$ Ophthalmol 2000;129:427-35.

11 Wensor M, McCarty CA, Taylor HR. Prevalence and risk factors for myopia in Victoria, Australia. Arch Ophthalmol 1999;117:658-63.
12 Attebo K, Ivers RO, Mitchell P. Refractive errors in an older population: the Blue Mountains Eye Study. Ophthalmology 1999;106:10066-72.

13 Global Initiative for the Elimination of Avoidable Blindness. World Health Organisation for the Prevention of Blindness and Deafness. WHO/PBL/97.61. Geneva: WHO, 1997.

14 Liou HL, McCarty CA, Jin CL, et al. Prevalence and predictors of undercorrected refractive errors in the Victorian population. Am f Ophthalmol 1999;127:590-6.

15 Livingston PM, Carson CA, Stanislavsky YL, et al. Methods for a population-based study of eye disease: the Melbourne Visual Impairment Project. Ophthalmic Epidemiol 1994;1: 139-48.

16 Allergan Humphrey. Humphrey Lens Analyser: Models $306,330,340$

17 Ferris FL, Kassoff A, Bresnick GH, et al. New visual acuity charts for clinical research. Am f Ophthalmol 1982;94:91-6.

18 Bailey IL, Lovie JE. New design principles for visual acuity letter charts. Am f Optom Physiol Opt 1974;53:740-5.

19 The Allergan Humphrey Automatic Refractor: Models 580, 585, 590. Operator's Manual. California: Allergan Humphrey, 1990.

20 Sperduto RD, Segel D, Roberts J, et al. Prevalence of myopia in the United States. Arch Ophthalmol 1983;101:405-7.

21 Dineen BP, Bourne RR, Modasser Ali S, et al. Prevalence Dineen BP, Bourne RR, Modasser Ali S, et al. Prevalence
and causes of visual impairment in Bangladeshi adultsand causes of visual impairment in Bangladeshi adultsBangladesh. Invest Ophthalmol Vis Sci 2001;42:S710.

22 Dandona L, Dandona R, Srinivas M, et al. Blindness in the Indian state of Andhra Pradesh. Invest Ophthalmol Vis Sci 2001;42:908-16. 